\title{
Prevotella nanceiensis sp. nov., isolated from human clinical samples
}

\author{
C. Alauzet, ${ }^{1,2}$ F. Mory, ${ }^{2}$ J.-P. Carlier, ${ }^{3}$ H. Marchandin,, ${ }^{4,5}$ E. Jumas-Bilak ${ }^{5}$
} and A. Lozniewski ${ }^{1,2}$

Correspondence

A. Lozniewski

a.lozniewski@chu-nancy.fr

\author{
${ }^{1}$ Université Nancy I, UMR CNRS 7565, UFR de Médecine, Laboratoire de Bactériologie, \\ Vandoeuvre-les-Nancy, France \\ ${ }^{2}$ Centre Hospitalier et Universitaire de Nancy, Hôpital Central, Laboratoire de Bactériologie, Nancy, \\ France \\ ${ }^{3}$ Institut Pasteur, Centre National de Référence des Bactéries Anaérobies et du Botulisme, Paris, \\ France \\ ${ }^{4}$ Centre Hospitalier et Universitaire de Montpellier, Hôpital Arnaud de Villeneuve, Laboratoire de \\ Bactériologie, Montpellier, France \\ ${ }^{5}$ Université Montpellier 1, UFR de Pharmacie, Laboratoire de Bactériologie-Virologie, EA 3755, \\ Montpellier, France
}

\begin{abstract}
Three strains of anaerobic, non-pigmented, Gram-negative bacilli isolated from various human clinical samples were characterized in terms of phenotypic and genotypic tests, including sequence analysis of $16 \mathrm{~S}$ rRNA and $r p o B$ genes. The strains were most closely related to the type strains of Prevotella marshii and Prevotella shahii on the basis of both 16S rRNA (89.8 and $89.0 \%$ identity, respectively) and $r p o B$ gene sequences ( 83.1 and $82.8 \%$ identity, respectively). Phylogenetic analysis showed that the isolates constituted a robust homogeneous group distinct from known species in the genus Prevotella. The rrn skeleton (as determined by PFGE) and the DNA G + C content, determined to be 39.4 mol\% for strain LBN $293^{\top}$, distinguished the novel isolates from the type strains of $P$. marshii and $P$. shahii. The three strains were saccharolytic and produced acetic, lactic and succinic acids as major metabolic end products. Polyphasic investigations supported the proposal of a novel species, Prevotella nanceiensis sp. nov., with LBN $293^{\top}\left(=\right.$ AIP $261.03^{\top}=$ CIP $108993^{\top}=$ CCUG $\left.54409^{\top}\right)$ as the type strain.
\end{abstract}

The genus Prevotella includes strictly anaerobic, Gramnegative, moderately saccharolytic, bile-sensitive rods that formerly belonged to the genus Bacteroides (Shah \& Collins, 1990). These bacteria, which are part of the human oral, intestinal and urogenital flora, may be involved in various infections of the head and neck, lower respiratory tract, central nervous system, abdominal and female genital tract and in bacteraemia (Jousimies-Somer et al., 2002). The use of molecular methods, such as $16 \mathrm{~S}$

\section{Abbreviation: ML, maximum likelihood.}

The GenBank/EMBL/DDBJ accession numbers for the $16 \mathrm{~S}$ rRNA and $r p o B$ gene sequences determined in this study are respectively AY957555 and EF405531 for P. nanceiensis LBN 293' ${ }^{\top}$, EF405529 and EF405532 for P. nanceiensis LBN 297 and EF405530 and EF405533 for $P$. nanceiensis LBN 298. Those for the rpoB gene sequences of $P$. marshii $\mathrm{E} 9.34^{\top}$ and $P$. shahii JCM $12083^{\top}$ are respectively EF405534 and EF405535.

Transmission electron micrographs of cells of strain LBN $293^{\top}$ and a comparison of its fatty acid profile with those of related type strains are available as supplementary material with the online version of this paper.
rRNA gene sequencing, for the identification of anaerobic bacteria has revealed that a significant proportion of strains did not correspond to species with validly published names (Jousimies-Somer, 1997; Jousimies-Somer et al., 2003) and has led to a great expansion of the genus Prevotella, with the description of ten novel species within the last 3 years. In this study, three strains of anaerobic Gram-negative rods, isolated from different human clinical samples and affiliated to the genus Prevotella by presumptive identification tests, were subjected to a comprehensive range of phenotypic, genotypic, genomic and phylogenetic tests.

Strains LBN $293^{\mathrm{T}}$ and LBN 297 were both recovered in pure culture. Strain LBN $293^{\mathrm{T}}$ was isolated in 2003 from blood cultures from a 78-year-old man (Mory et al., 2005) and strain LBN 297 was isolated in 2004 from lung abscess pus from a 67-year-old man. Strain LBN 298 was isolated in 2005 from a broncho-alveolar lavage fluid from a 66year-old woman. The broncho-alveolar lavage fluid also contained Pseudomonas aeruginosa and a coagulase-negative Staphylococcus sp. Strains were grown at $36{ }^{\circ} \mathrm{C}$ on Brucella agar supplemented with $5 \%$ sheep blood, haemin 
and vitamin $\mathrm{K}_{1}(\mathrm{BBA})$ in an anaerobic chamber (Concept 1000; Ruskinn).

DNA was extracted by using the QIAamp DNA Mini kit (Qiagen). The 16S rRNA gene was amplified by PCR and sequenced as described previously (Carlier et al., 2004). A $374 \mathrm{bp}$ fragment of the gene $r p o B$ was amplified using the primer pair Prev3250F (5'-AACCCGTTGGGTGTGCC-3') and Prev3623R (5'-AGIGCCCAAACCTCCATCTCTCC-3') (Berger et al., 2005). Nucleotide sequences were analysed by using SeqScape software (version 2.5; Applied Biosystems). The sequences were compared to those deposited in the GenBank and Ribosomal Database Project II databases using the BLAST program (Altschul et al., 1997) and Seqmatch program (Cole et al., 2007), respectively. The isolates displayed the highest $16 \mathrm{~S}$ rRNA gene sequence similarity to members of the genus Prevotella. Maximum similarity $(99.4 \%)$ was observed with the sequence of Prevotella sp. oral clone BI027, obtained from human subgingival plaque (Paster et al., 2001). The 16S rRNA gene sequences were aligned against sequences of all known Prevotella type strains and that of Prevotella oral clone BI027 using the DIALIGN program (Morgenstern, 2002). The distance matrix constructed using the Similarity table program of the PHYLIP package (Felsenstein, 1993) showed that strains LBN $293^{\mathrm{T}}$, LBN 297 and LBN 298 shared more than $99.6 \%$ of their $16 \mathrm{~S}$
rRNA gene nucleotide positions. The best sequence matches with strains of species with validly published names were obtained with Prevotella marshii E9.34 $4^{\mathrm{T}}$ and Prevotella shahii JCM $12083^{\mathrm{T}}$, but the similarity levels ( 89.8 and $89.0 \%$, respectively) were relatively low. The three isolates displayed $100 \%$ identity in $r p o B$ gene sequences. Maximum similarity was again observed with the sequences of $P$. marshii E9.34 ${ }^{\mathrm{T}}$ and P. shahii JCM $12083^{\mathrm{T}}$ (83.1 and $82.8 \%$, respectively). Altogether, the sequencing results suggested that the three strains belonged to a new taxon. This prompted us to investigate the taxonomic position of these strains by a polyphasic approach.

Evolutionary trees were reconstructed using the PHYLIP suite of programs (Felsenstein, 1993) by maximumparsimony (Kluge \& Farris, 1969) and by neighbourjoining (algorithm F84 for substitution model) (Saitou \& Nei, 1987; Kishino \& Hasegawa, 1989). The robustness of the nodes was evaluated by 1000 bootstrap replications using SEQBOOT and CONSENSE programs (Felsenstein, 1993). The maximum-likelihood (ML) tree was reconstructed using phyML software with GTR (gamma distribution and invariable sites) as the substitution model and 100 bootstrap replications (Guindon \& Gascuel, 2003). The $16 \mathrm{~S}$ rRNA gene-based ML phylogenetic tree is shown in Fig. 1. Nodes labelled by asterisks were found by all three

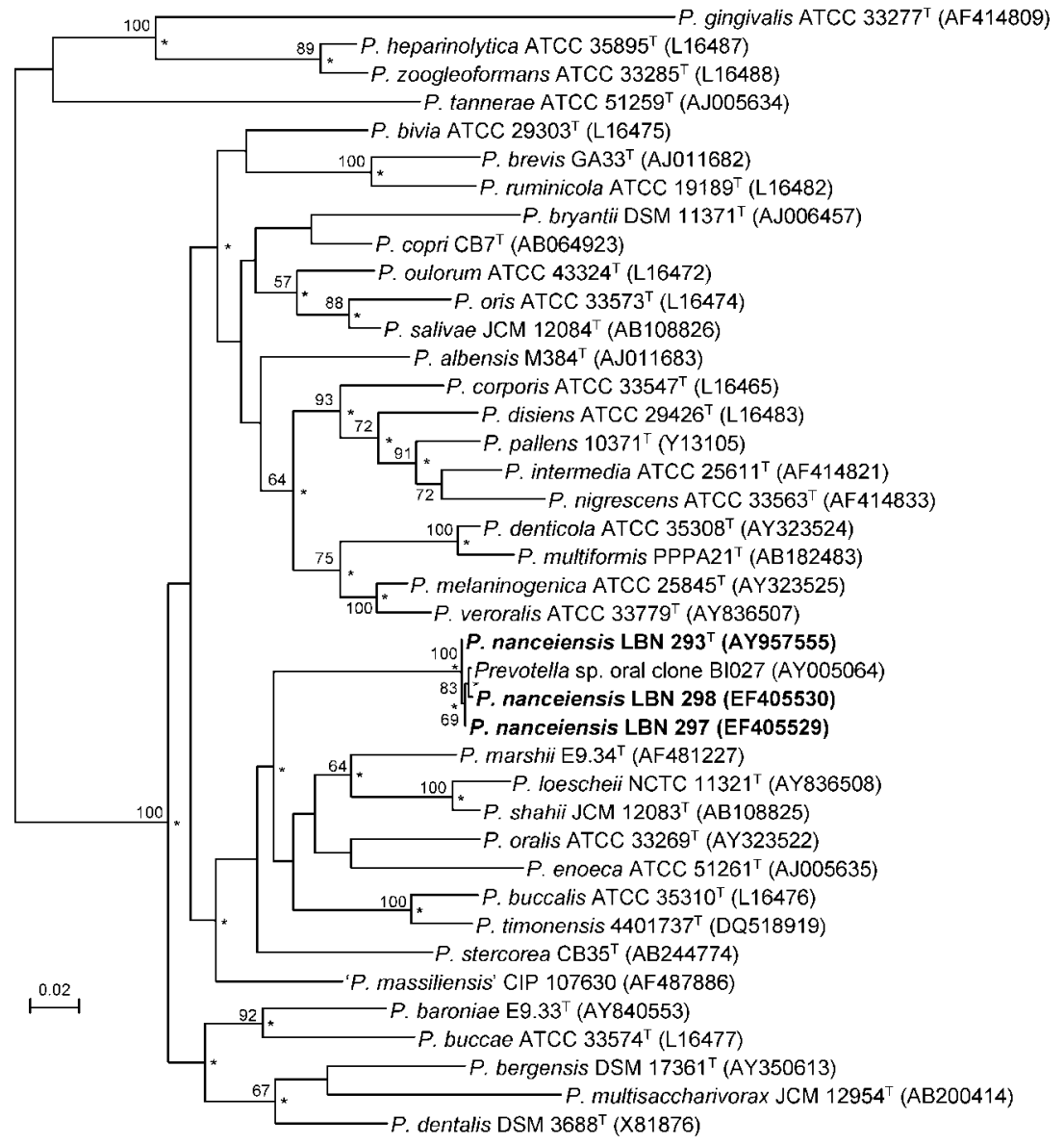

Fig. 1. $M L$ phylogenetic tree for $16 \mathrm{~S}$ rRNA gene sequences showing the relationship between the novel strains (Prevotella nanceiensis sp. nov.) and the other members of the genus Prevotella. The sequence of Porphyromonas gingivalis ATCC $33277^{\top}$ was used as an outgroup. Bootstrap values $>50$ are indicated at corresponding nodes. Consensus nodes observed in the ML, neighbour-joining and parsimony trees are labelled with asterisks. Sequence accession numbers are in parentheses. Bar, 0.02 substitutions per site. 
phylogenetic methods, but other branches moved according to the phylogenetic method. Strains LBN $293^{\mathrm{T}}$, LBN 297 and LBN 298 formed a robust homogeneous group distinct from other species of the genus Prevotella.

The DNA G + C content of strain LBN $293^{\mathrm{T}}$, determined by HPLC at the Identification Service of the DSMZ (Deutsche Sammlung von Mikroorganismen und Zellkulturen, Braunschweig, Germany), was $39.4 \mathrm{~mol} \%$. This value is in accordance with those reported for the genus Prevotella (39-60 mol\%) (Willems \& Collins, 1995; Avguštin et al., 1997) and was clearly distinct from the DNA G+C contents determined for the most closely related species, $P$. marshii (51.0 mol\%; Downes et al., 2005) and P. shahii (44.3 mol\%; Sakamoto et al., 2004).

Large-scale chromosome structure analysis was previously described as a sensitive indicator of phylogenetic relationships between bacteria (Liu et al., 1999; Marchandin et al., 2003a; Jumas-Bilak et al., 2005). Chromosome size and rrn skeletons of the three isolates were studied in comparison with P. marshii DSM $16973^{\mathrm{T}}$ and P. shahii DSM $15611^{\mathrm{T}}$ using PFGE, as described previously (Jumas-Bilak et al., 1998; Marchandin et al., 2003a, b). All three strains studied possess a unique and circular chromosome (data not shown). The chromosome of the novel strains was 3.02 to $3.09 \mathrm{Mb}$ in size, similar to the $P$. marshii chromosome $(2.95 \mathrm{Mb})$ but clearly distinct from the $P$. shahii chromosome $(4.01 \mathrm{Mb})$. I-CeuI profiles showed that all the strains tested possess four rrn operons (Fig. 2). The rrn skeleton distinguished the novel strains from their most closely related phylogenetic neighbours, $P$. marshii and $P$. shahii, each species exhibiting a specific I-CeuI profile (Fig. 2).

The strains were obligately anaerobic, non-spore-forming, non-motile, Gram-negative coccoid and short rods. After

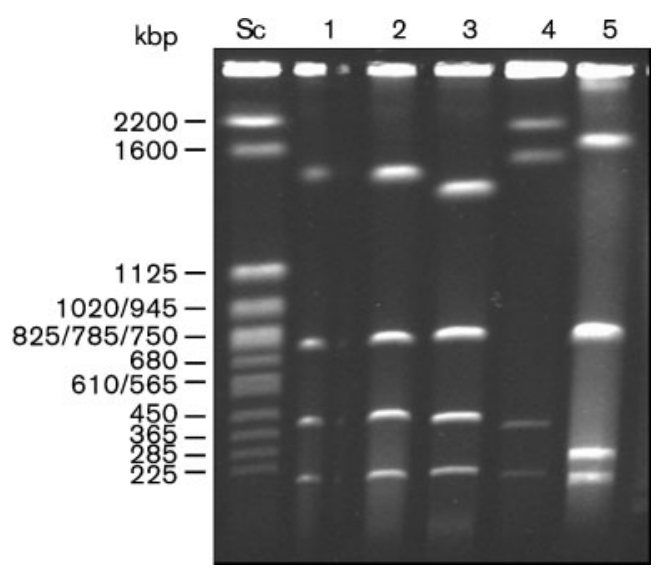

Fig. 2. PFGE migration of I-Ceul-restricted DNAs. Lanes: $1, P$. nanceiensis LBN 298; 2, $P$. nanceiensis LBN 297; 3, $P$. nanceiensis LBN 293 ${ }^{\top} ; 4$, P. shahii DSM $15611^{\top} ; 5$, P. marshii DSM $16973^{\top}$. Lane Sc, Saccharomyces cerevisiae chromosomes used as molecular size marker. Sizes are indicated in kilobases.
4 days incubation on BBA, colonies were $0.5-1 \mathrm{~mm}$ in diameter, circular, entire, slightly convex and smooth, white, non-pigmented and surrounded by a $\beta$-haemolysis zone. For examination of the cell-wall ultrastructure of strain LBN $293^{\mathrm{T}}$, cells were prepared as described previously (Carlier et al., 2004) and electron photomicrographs were taken with a JEOL 1010 transmission electron microscope operating at $80 \mathrm{kV}$. Rods, $0.4-0.5 \times 0.5-1.0 \mu \mathrm{m}$ in size, were observed. Transmission electron microscope examination of ultrathin sections of strain LBN $293^{\mathrm{T}}$ showed the presence of a typical Gram-negative cell wall composed of a thin peptidoglycan layer surrounded by an outer membrane (see Supplementary Fig. S1 in IJSEM Online).

All strains were susceptible to bile ( $1 \mathrm{mg}$ tablet) and resistant to kanamycin ( $1 \mathrm{mg}$ disc), vancomycin (5 $\mu \mathrm{g}$ tablet) and colistin $(10 \mu \mathrm{g}$ tablet $)$.

Biochemical tests were performed in triplicate using the API 20A anaerobe identification kit (bioMérieux) as recommended by the manufacturer. Xylan fermentation was determined in trypticase/yeast extract broth as recommended by Holdeman et al. (1977). Metabolic end products were assayed by quantitative gas chromatography as described previously (Carlier, 1985). Enzyme profiles were generated with the Rapid ID 32A anaerobe identification kit (bioMérieux), according to the manufacturer's instructions, and performed in triplicate. The results of these tests are given in the species description.

Characteristics summarized in Table 1 for the novel strains and related Prevotella species showed that the novel strains were phenotypically very similar to Prevotella buccalis and Prevotella veroralis. However, the novel strains could be distinguished from $P$. buccalis by the absence of arginine arylamidase production and from $P$. veroralis by the absence of fermentation of xylan.

The cellular fatty acid composition of strain LBN $293^{\mathrm{T}}$ was determined by using the MIDI Microbial Identification System at the Identification Service of the DSMZ (Supplementary Table S1). Analysis of cellular fatty acids showed that strain LBN $293^{\mathrm{T}}$ had a low similarity index (0.106) to the Prevotella loescheii entry found in MIDI library version 3.8. The high level of summed feature 11 and smaller amount of $\mathrm{C}_{18: 1} \omega 9 c$ are differential characteristics between strain LBN $293^{\mathrm{T}}$ and closely related species.

On the basis of the above-mentioned findings, we propose that strains LBN $293^{\mathrm{T}}$, LBN 297 and LBN 298 should be classified within a novel species of the genus Prevotella, Prevotella nanceiensis sp. nov.

\section{Description of Prevotella nanceiensis sp. nov.}

Prevotella nanceiensis (nan.ce.i.en'sis. N.L. fem. adj. nanceiensis pertaining to Nanceium, the old name of Nancy, the French city where the strains supporting the description of the species were isolated). 
Table 1. Differential phenotypic characteristics of Prevotella nanceiensis sp. nov. and related Prevotella species

Species: 1, P. nanceiensis sp. nov. (strains LBN 293 ${ }^{\mathrm{T}}$, LBN 297 and LBN 298); 2, P. bivia; 3, P. disiens; 4, P. buccalis; 5, P. enoeca; $6, P$. oralis; 7, P. oulorum; 8 , P. veroralis; 9, P. shahii; 10, P. marshii; 11, P. loescheii. + , Positive; -, negative; $v$, variable; ND, no data available. Data for reference species were taken from Downes et al. (2005), Jousimies-Somer et al. (2002), Sakamoto et al. (2004), Shah \& Collins (1990), Watabe et al. (1983) and Wu et al. (1992).

\begin{tabular}{|c|c|c|c|c|c|c|c|c|c|c|c|}
\hline Characteristic & 1 & 2 & 3 & 4 & 5 & 6 & 7 & 8 & 9 & 10 & 11 \\
\hline $\begin{array}{l}\text { Pigment } \\
\text { production }\end{array}$ & - & - & - & - & - & - & - & - & + & - & + \\
\hline Fermentation of: & & & & & & & & & & & \\
\hline Cellobiose & $\mathrm{V}^{*}$ & - & - & + & - & + & - & + & - & - & + \\
\hline Lactose & $+^{*}$ & + & - & + & + & + & + & + & + & - & + \\
\hline Mannose & $+^{*}$ & + & - & + & $\mathrm{v}$ & + & + & + & + & $\mathrm{V}$ & + \\
\hline Raffinc & $+^{*}$ & - & - & + & - & + & + & + & + & - & + \\
\hline Rhamno & $-*$ & - & - & - & ND & + & - & - & - & - & - \\
\hline Salici & $-{ }^{*}$ & - & - & - & - & + & - & - & - & - & - \\
\hline Sucrose & $+^{*}$ & - & - & + & - & + & + & + & + & - & + \\
\hline Xyla & - & - & $\mathrm{ND}$ & - & ND & - & - & + & $\mathrm{ND}$ & $\mathrm{ND}$ & $\mathrm{V}$ \\
\hline $\begin{array}{l}\text { Aesculin } \\
\text { hydrolysis }\end{array}$ & $+^{*}$ & - & - & + & $\mathrm{v}$ & + & + & + & - & - & + \\
\hline Gelatin hydrolysis & $-{ }^{*}$ & + & + & - & + & V & - & $\mathrm{V}$ & + & + & + \\
\hline Catalase & $-{ }^{\star}$ & - & - & - & - & - & + & - & - & - & - \\
\hline
\end{tabular}

${ }^{\star}$ As determined using the API $20 \mathrm{~A}$ anaerobe identification kit.

Cells are obligately anaerobic, non-spore-forming, nonmotile, Gram-negative coccoid and short rods (0.4$0.5 \times 0.5-1.0 \mu \mathrm{m})$. After 4 days incubation on BBA, colonies are $0.5-1 \mathrm{~mm}$ in diameter, circular, entire, slightly convex and smooth, white, non-pigmented and surrounded by a $\beta$-haemolysis zone. Growth is inhibited in the presence of bile. Strains are saccharolytic and ferment glucose, lactose, maltose, mannose, raffinose and sucrose. Fermentation of cellobiose is variable among strains. Acid is not produced from arabinose, glycerol, mannitol, melezitose, rhamnose, salicin, sorbitol, trehalose, xylan or xylose. The major metabolic end products are acetic, lactic and succinic acids. Aesculin is hydrolysed. Gelatin and urea are not hydrolysed. Indole and catalase are not produced and nitrate is not reduced. All strains are positive for $\alpha$ galactosidase, $\beta$-galactosidase, $\beta$-galactosidase-6-phosphate, $\alpha$-glucosidase, $N$-acetyl- $\beta$-glucosaminidase, alkaline phosphatase, leucyl glycine arylamidase, alanine arylamidase, $\alpha$-fucosidase and glutamyl glutamic acid arylamidase in the Rapid ID 32A identification panel, while reactions for mannose and raffinose fermentation and for $\beta$ glucosidase are variable among strains. All strains are negative for the remaining 16 tests, resulting in a Rapid ID $32 \mathrm{~A}$ profile of $47^{0} / 1 \frac{1}{5} /^{7} 440222$. The fatty acid profile predominantly comprises iso- $\mathrm{C}_{15: 0}$, anteiso- $\mathrm{C}_{15: 0}, \mathrm{C}_{16: 0}$, $\mathrm{C}_{16: 0} 3-\mathrm{OH}, \mathrm{C}_{18: 2} \omega 9,12 c$ and summed feature 11 (iso$\mathrm{C}_{17: 0} 3-\mathrm{OH}$ and/or $\mathrm{C}_{18: 2}$ dimethylacetal). Chromosomal genomic size ranges from 3.02 to $3.09 \mathrm{Mb}$, with four $\mathrm{rrn}$ operon copies. The DNA G $+\mathrm{C}$ content of the type strain is $39.4 \mathrm{~mol} \%$.

The type strain is LBN $293^{\mathrm{T}}\left(=\mathrm{AIP} 261.03^{\mathrm{T}}=\mathrm{CIP} 108993^{\mathrm{T}}\right.$ $=$ CCUG $54409^{\mathrm{T}}$ ), isolated from a blood culture. Two other strains were recovered from clinical respiratory samples.

\section{Acknowledgements}

The authors are grateful to M.-C. Prevost and A. Mallet (Plate-forme de Microscopie Electronique, Institut Pasteur, Paris) for performing the transmission electron microscopy, Corinne Teyssier for her help concerning PFGE and Isabelle Scholtus, Monique Chaon, Elise Pernot and Marie Bedora-Faure for their technical assistance.

\section{References}

Altschul, S. F., Madden, T. L., Schäffer, A. A., Zhang, J., Zhang, Z., Miller, W. \& Lipman, D. J. (1997). Gapped BLAST and PSI-BLAST: a new generation of protein database search programs. Nucleic Acids Res 25, 3389-3402.

Avguštin, G., Wallace, R. J. \& Flint, H. J. (1997). Phenotypic diversity among ruminal isolates of Prevotella ruminicola: proposal of Prevotella brevis sp. nov., Prevotella bryantii sp. nov., and Prevotella albensis sp. nov. and redefinition of Prevotella ruminicola. Int J Syst Bacteriol 47, 284-288.

Berger, P., Adékambi, T., Mallet, M.-N. \& Drancourt, M. (2005). Prevotella massiliensis sp. nov. isolated from human blood. Res Microbiol 156, 967-973.

Carlier, J.-P. (1985). Gas chromatography of fermentation products: its application in diagnosis of anaerobic bacteria. Bull Inst Pasteur 83, 57-69.

Carlier, J.-P., K'ouas, G., Bonne, I., Lozniewski, A. \& Mory, F. (2004). Oribacterium sinus gen. nov., sp. nov., within the family 'Lachnospiraceae' (phylum Firmicutes). Int J Syst Evol Microbiol 54, 1611-1615.

Cole, J. R., Chai, B., Farris, R. J., Wang, Q., Kulam-Syed-Mohideen, A. S., McGarrell, D. M., Bandela, A. M., Cardenas, E., Garrity, G. M. \& Tiedje, J. M. (2007). The ribosomal database project (RDP-II): introducing myRDP space and quality controlled public data. Nucleic Acids Res 35, D169-D172.

Downes, J., Sutcliffe, I., Tanner, A. C. \& Wade, W. G. (2005). Prevotella marshii sp. nov. and Prevotella baroniae sp. nov., isolated from the human oral cavity. Int J Syst Evol Microbiol 55, 1551-1555.

Felsenstein, J. (1993). PHYLIP (phylogeny inference package), version 3.5c. Distributed by the author. Department of Genome Sciences, University of Washington, Seattle, USA.

Guindon, S. \& Gascuel, O. (2003). A simple, fast, and accurate algorithm to estimate large phylogenies by maximum likelihood. Syst Biol 52, 696-704.

Holdeman, L. V., Cato, E. P. \& Moore, W. E. C. (1977). Anaerobe Laboratory Manual, 4th edn. Blacksburg, VA: Virginia Polytechnic Institute and State University.

Jousimies-Somer, H. (1997). Recently described clinically important anaerobic bacteria: taxonomic aspects and update. Clin Infect Dis $\mathbf{2 5}$ (Suppl. 2), S78-S87.

Jousimies-Somer, H., Summanen, P., Citron, D. M., Baron, E. J., Wexler, H. M. \& Finegold, S. M. (2002). Wadsworth-KTL Anaerobic Bacteriology Manual, 6th edn. Belmont, CA: Star Publishing. 
Jousimies-Somer, H. R., Summanen, P. H., Wexler, H., Finegold, S. M., Gharbia, S. E. \& Shah, H. N. (2003). Bacteroides, Porphyromonas, Prevotella, Fusobacterium, and other anaerobic gram-negative bacteria. In Manual of Clinical Microbiology, 6th edn, vol. 1, pp. 880-901. Edited by P. R. Murray, E. J. Baron, J. H. Jorgensen, M. A. Pfaller \& R. H. Yolken. Washington, DC: American Society for Microbiology.

Jumas-Bilak, E., Michaux-Charachon, S., Bourg, G., O'Callaghan, D. \& Ramuz, M. (1998). Differences in chromosome number and genome rearrangements in the genus Brucella. Mol Microbiol 27, 99-106.

Jumas-Bilak, E., Jean-Pierre, H., Carlier, J.-P., Teyssier, C., Bernard, K., Gay, B., Campos, J., Morio, F. \& Marchandin, H. (2005). Dialister micraerophilus sp. nov. and Dialister propionicifaciens sp. nov., isolated from human clinical samples. Int J Syst Evol Microbiol 55, 2471-2478.

Kishino, H. \& Hasegawa, M. (1989). Evaluation of the maximum likelihood estimate of the evolutionary tree topologies from DNA sequence data, and the branching order in Hominoidea. J Mol Evol 29, 170-179.

Kluge, A. \& Farris, J. (1969). Quantitative phyletics and the evolution of anurans. Syst Zool 18, 1-32.

Liu, S.-L., Schryvers, A. B., Sanderson, K. E. \& Johnston, R. N. (1999). Bacterial phylogenetic clusters revealed by genome structure. J Bacteriol 181, 6747-6755.

Marchandin, H., Jumas-Bilak, E., Gay, B., Teyssier, C., Jean-Pierre, H., Siméon de Buochberg, M., Carrière, C. \& Carlier, J.-P. (2003a). Phylogenetic analysis of some Sporomusa sub-branch members isolated from human clinical specimens: description of Megasphaera micronuciformis sp. nov. Int J Syst Evol Microbiol 53, 547-553.

Marchandin, H., Teyssier, C., Siméon de Buochberg, M., JeanPierre, H., Carrière, C. \& Jumas-Bilak, E. (2003b). Intra-chromosomal heterogeneity between the four 16S rRNA gene copies in the genus Veillonella: implications for phylogeny and taxonomy. Microbiology 149, 1493-1501.
Morgenstern, B. (2002). A simple and space-efficient fragmentchaining algorithm for alignment of DNA and protein sequences. Appl Math Lett 15, 11-16.

Mory, F., Carlier, J.-P., Alauzet, C., Thouvenin, M., Schuhmacher, H. \& Lozniewski, A. (2005). Bacteremia caused by a metronidazoleresistant Prevotella sp. strain. J Clin Microbiol 43, 5380-5383.

Paster, B. J., Boches, S. K., Galvin, J. L., Ericson, R. E., Lau, C. N., Levanos, V. A., Sahasrabudhe, A. \& Dewhirst, F. E. (2001). Bacterial diversity in human subgingival plaque. J Bacteriol 183, 3770-3783.

Saitou, N. \& Nei, M. (1987). The neighbor-joining method: a new method for reconstructing phylogenetic trees. Mol Biol Evol 4, 406-425.

Sakamoto, M., Suzuki, M., Huang, Y., Umeda, M., Ishikawa, I. \& Benno, Y. (2004). Prevotella shahii sp. nov. and Prevotella salivae sp. nov., isolated from the human oral cavity. Int J Syst Evol Microbiol 54, 877-883.

Shah, H. N. \& Collins, M. D. (1990). Prevotella, a new genus to include Bacteroides melaninogenicus and related species formerly classified in the genus Bacteroides. Int J Syst Bacteriol 40, 205-208.

Watabe, J., Benno, Y. \& Mitsuoka, T. (1983). Taxonomic study of Bacteroides oralis and related organisms and proposal of Bacteroides veroralis sp. nov. Int J Syst Bacteriol 33, 57-64.

Willems, A. \& Collins, M. D. (1995). 16S rRNA gene similarities indicate that Hallella seregens (Moore and Moore) and Mitsuokella dentalis (Haapasalo et al.) are genealogically highly related and are members of the genus Prevotella: emended description of the genus Prevotella (Shah \& Collins) and description of Prevotella dentalis comb. nov. Int J Syst Bacteriol 45, 832-836.

Wu, C. C., Johnson, J. L., Moore, W. E. C. \& Moore, L. V. H. (1992). Emended descriptions of Prevotella denticola, Prevotella loescheii, Prevotella veroralis, and Prevotella melaninogenica. Int J Syst Bacteriol 42, 536-541. 